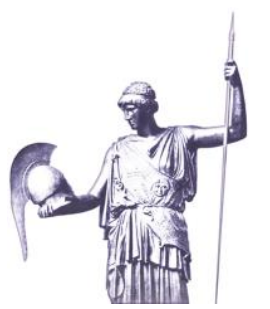

Connections: The Quarterly Journal

ISSN 1812-1101, e-ISSN 1812-2973

Тодор Тагарев, Connections QJ 18, № 1-2 (2019): 5-11

https://doi.org/10.11610/Connections.rus.18.1-2.00

Редакционная статья

\title{
Теория и современная практика сдерживания в международной безопасности
}

\section{Tодор Тагарев}

Центр менеджмента безопасности и обороны, Институт ИКТ Болгарской академии наук, http://www.iict.bas.bg/EN

Резюме: Теория сдерживания возникла с появлением ядерного оружия для решения проблем подготовки и предотвращения полномасштабной ядерной войны между Соединенными Штатами и Советским Союзом. Статьи в этом специальном выпуске вписаны в контекст периода после окончания Холодной войны с возрождающейся и агрессивной Россией. В сборнике статей дается краткое описание теории сдерживания, нынешней практики ее применения для сдерживания и, при необходимости, защиты с помощью обычных сил НАТО и восточного фланга Европы от агрессии, а также критический анализ ее связи с кибер и гибридной войной.

Ключевые слова: сдерживание, НАТО, восточный фланг, передовое присутствие сил на передовых рубежах, конвенциональные силы, киберсфера, кибербезопасность, кибероперации, правовая основа, гибридное влияние.

Сдерживание практиковалось на протяжении веков, чтобы отговорить оппонента от использования курса действий, связанного с принуждением, например, от вооруженного нападения. Эта концепция стала предметом ожесточенных дебатов с появлением ядерного оружия. К 1960-м годам ра- 
боты Бернарда Броди, ${ }^{1}$ Германа Кана, ${ }^{2}$ Гленна Х. Снайдера, ${ }^{3}$ Томаса С. Шеллинга ${ }^{4}$ и других сформировали совокупность знаний, позволяющих разработать стратегии и политику для ядерного противостояния во время Холодной войны и избежать ядерного конфликта.

Применение теории сдерживания во время Холодной войны привело к равновесию между ядерными арсеналами двух ведущих ядерных держав Советского Союза и Соединенных Штатов Америки, что гарантировало, что в случае полномасштабной ядерной войны как нападающая, так и обороняющаяся стороны будут уничтожены. ${ }^{5}$

С ядерной разрядкой и окончанием Холодной войны интерес к теории сдерживания утих. На практике сдерживание все еще гарантировалось, хотя и на более низком уровне сил. Например, в то время как в конце Холодной войны Соединенные Штаты поддерживали около 7300 единиц ядерного оружия, развернутых в Европе для обеспечения гарантий безопасности союзникам по НАТО, с тех пор эти силы были сокращены на 90 процентов. ${ }^{6}$

Интерес к сдерживанию возобновился в последние годы. Одной из причин было приостановление действия Договора о ракетах средней и меньшей дальности (РСМД) в начале 2019 года ${ }^{7}$ и предстоящее истечение срока действия Нового договора о сокращении стратегических вооружений (новый $\mathrm{CHB}){ }^{8}$ а также необходимость найти новый баланс с учетом ядерных

1 Bernard Brodie, ed., The Absolute Weapon: Atomic Power and World Order (New York: Harcourt, Brace and Company, 1946); Bernard Brodie, Strategy in the Missile Age (Santa Monica, CA: RAND, 1969).

2 Herman Kahn, On Thermonuclear War (Princeton: Princeton University Press, 1960).

3 Glenn H. Snyder, Deterrence and Defense: Toward a Theory of National Security (Princeton, NJ: Princeton University Press, 1961).

4 Thomas C. Schelling, The Strategy of Conflict, with a new preface by the author (Cambridge, MA: Harvard University Press, 1980); Thomas C. Schelling, Arms and Influence, with a new preface and afterword (New Haven: Yale University Press, 2008).

5 James E. Doyle, "Why Eliminate Nuclear Weapons?" Survival 55, no. 1 (2013): 7-34, https://doi.org/10.1080/00396338.2013.767402; Tom de Castella, "How Did We Forget about Mutually Assured Destruction?" BBC News, February 15, 2012, https://www.bbc.com/news/magazine-17026538.

6 Jessica Cox, "Nuclear Deterrence Today," NATO Review, June 8, 2020, www.nato.int/ docu/review/articles/2020/06/08/nuclear-deterrence-today/index.html.

7 Simon Lunn and Nicholas Williams, "The Demise of the INF Treaty: What Are the Consequences for NATO," Policy Brief, European Leadership Network, February 11, 2019, https://www.europeanleadershipnetwork.org/policy-brief/the-demise-of-theinf-treaty-what-are-the-consequences-for-nato/.

8 Kingston Reif, "New START at a Glance," Fact Sheets \& Briefs, Arms Control Association, January 2020, https://www.armscontrol.org/factsheets/NewSTART. 
возможностей других игроков, в частности Китая. ${ }^{9}$ Другая причина - незаконная аннексия Крымского полуострова Российской Федерацией и ее агрессивные кибер и гибридные действия против членов и партнеров НАТО.

В этом специальном выпуске Connections: The Quarterly Journal основное внимание уделяется вышеупомянутым действиям и использованию обычных, кибер средств и средств дезинформации для сдерживания агрессии.

В первой работе полковник Даррелл Драйвер, директор департамента европейских исследований Военного колледжа армии США, закладывает фундамент, рассматривая теоретические основы сдерживания и две его основные концепции - сдерживание наказанием и сдерживание воспрещением. ${ }^{10}$ На этой основе д-р Драйвер критически оценивает позицию НАТО на его восточном фланге и приходит к выводу, что за счет «усиленного передового присутствия» в странах Балтии и Польше, «адаптированного передового присутствия» в Болгарии и Румынии, регулярных учений в Черном море, создания Совместной оперативной группы очень высокой готовности (СОВГ) и создания формирований для интеграции сил НАТО (ФИСН) в семи странах восточного фланга, союзники уже “дали свой вклад», таким образом обеспечивая единый ответ Североатлантического союза на акт агрессии и делая неизбежным ответный удар НАТО. С увеличением оборонных бюджетов в соответствии с обещанием, принятым на саммите в Уэльсе, Европейской инициативой сдерживания Соединенных Штатов, так называемым решением «четырех 30» на саммите НАТО в Брюсселе и развитием «военного Шенгена» в Европе, союзники уже переходят от сдерживания наказанием к сдерживанию воспрещением.

Полковник Драйвер также напоминает нам о требованиях к защите и сдерживанию, сформулированных генерал-лейтенантом (в отставке) Беном Ходжесом, бывшим командующим армией США в Европе, для обеспечения эффективного раннего предупреждения, наличия боеспособных национальных сил, соответствующей инфраструктуры и предварительно размещенных запасов. ${ }^{11}$ Велизар Шаламанов, Павел Анастасов и Георги Цветков развивают этот момент дальше, начиная с ангажемента относительно оборонных бюджетов, принятого на саммите в Уэльсе и его реализации на национальном уровне на примере Болгарии. ${ }^{12}$ Затем авторы рассматривают

9 Lunn and Williams, "The Demise of the INF Treaty.

10 Darrell W. Driver, "Deterrence in Eastern Europe in Theory and Practice," Connections: The Quarterly Journal 18, no. 1-2 (2019): 11-24.

11 Ben Hodges, Janusz Bugajski, and Peter B. Doran, "Securing the Suwałki Corridor: Strategy, Statecraft, Deterrence, and Defense" (Washington, DC: Center for European Policy Analysis, July 2018).

12 Velizar Shalamanov, Pavel Anastasov, and Georgi Tsvetkov, "Deterrence and Defense at the Eastern Flank of NATO and the EU: Readiness and Interoperability in the Context of Forward Presence, Connections: The Quarterly Journal 18, no.1-2 (2019): 25-42. 
опыт сотрудничества в сфере обороны в Восточной и Юго-Восточной Европе, подчеркивают преимущества многонационального приобретения необходимых способностей и подробно исследуют потенциальные многонациональные форматы, инициативы и источники финансирования, уделяя особое внимание приобретению информационных и коммуникационных технологий, сенсоров и систем командования и управления или систем C4ISR, а также многонациональному образованию и обучению. Многонациональные формирования на тактическом уровне и проекты по приобретению, реализуемые в формате НАТО и/или ЕС, внесут свой вклад в развитие оперативно совместимых способностей и солидарности, и, таким образом, в более эффективную защиту восточного фланга Европы.

В третьей статье этого номера Рослав Ежевский закладывает основу для обсуждения применимости концепции сдерживания действий, связанных с принуждением, с использованием набора гибридных инструментов. ${ }^{13}$ В случае с Латвией автор демонстрирует как Россия пытается влиять на национальный курс в своих интересах, сочетая экономическое и финансовое влияние, коррупцию, эксплуатацию меньшинства граждан русского происхождения, пропагандистские и дезинформационные кампании, организованную преступность в России и широкомасштабные военные учения, проводимые на границах страны. Автор предлагает идеи о том, как защититься, если не сдержать, такую принуждающую деятельность, включая примеры из опыта Финляндии. Тем не менее, заключает он, «междоменное принуждение усилится, и Россия будет проверять сплоченность НАТО».

Кибератаки и кампании дезинформации в сетевых СМИ являются одними из основных инструментов гибридного влияния. Следующие две статьи посвящены применимости концепции сдерживания к киберпространству. Во-первых, Мика Керттунен из Института киберполитики в Тарту, Эстония, излагает критику теории сдерживания в целом и ее применимости к киберпространству, в частности. ${ }^{14}$ Среди аргументов в подтверждение последнего положения, автор указывает на изменившийся контекст для киберсдерживания (по сравнению с применением ядерного оружия), соответственно, более высокую степень терпимости к кибератакам, более широкий спектр подходов к сдерживанию и использование более тонких инструментов, в том числе позитивных программ с наградами. В своем заключении г-н Керттунен заявляет, что «сдерживание - это громоздкий и неподходящий инструмент для понимания киберсферы». ${ }^{15}$

13 Rosław Jeżewski, "Cross-domain Coercion as Russia's Endeavor to Weaken the Eastern Flank of NATO: A Latvian Case Study," Connections: The Quarterly Journal 18, no. 1 (2019): 43-60.

14 Mika Kerttunen, "Beyond Punishment: Deterrence in the Digital Realm," Connections: The Quarterly Journal 18, no. 1 (2019): 61-68.

15 Kerttunen, "Beyond Punishment: Deterrence in the Digital Realm," 67. 
С другой стороны, Мануэль Фишер утверждает, что хотя киберсфера требует некоторых особых соображений, сдерживание как «классический инструмент» в международных отношениях может укреплять интересы национальной безопасности. ${ }^{16}$ Фишер, выпускник магистерской программы исследований по международной безопасности Европейского центра исследований по вопросам безопасности им. Джорджа К. Маршалла, рассматривает последствия концепции сдерживания для киберпространства по шести направлениям: время, наличные «силы» (ответственные организации с учетом уязвимостей цепочки поставок), выживание, средства защиты и потенциал, а также проблемы атрибуции - с последующим изучением правовых рамок для включения кибер-деятельности в международные отношения. На основе анализа, представленного в этом специальном выпуске, Фишер приходит к выводу, что «[даже] в киберэпохе сдерживание может быть мощным инструментом государственности и способствовать защите интересов государства в области национальной безопасности. ${ }^{17}$

Хотя Мика Керттунен и Мануэль Фишер, кажется, придерживаются противоположных взглядов, их выводы не так уж сильно отличаются. Хотя и в разной степени, оба автора видят ограничения сдерживания посредством наказания/возмездия в киберпространстве и отдают предпочтение сдерживанию посредством воспрещения, в том числе посредством соответствующего дизайна сетей, лучшей защиты, повышения устойчивости, государственно-частного партнерства и т.д. Они также указывают на ценность более позитивных подходов, на необходимость усиления международных режимов для обеспечения «сдерживания с помощью нормативных табу» и на построение взаимозависимостей в международной системе, или на так называемого "сдерживания путём обвязывания». ${ }^{18}$

В докладе Тамары Малярчук, Юрия Даника и Чада Бриггса рассматривается использование кибератак против энергетической инфраструктуры в качестве одного из инструментов в наборе средств, используемых Российской Федерацией в ее продолжающемся противостоянии с Украиной. ${ }^{19}$ Текущая украинская доктрина рассматривает такие кибератаки (постоянные комплексные угрозы, атаки на системы промышленного контроля) наряду с использованием социальных сетей, атаками на банковскую систему и использованием уязвимостей цепочки поставок. Как и в предыдущих двух статьях этого выпуска, авторы идентифицируют более совершенную защиту, отказоустойчивость и безопасность цепочки поставок в качестве ключевых факторов защиты от кибератак.

16 Manuel Fischer, "The Concept of Deterrence and its Applicability in the Cyber Domain," Connections: The Quarterly Journal 18, no. 1 (2019): 69-92.

17 Fischer, "The Concept of Deterrence and its Applicability in the Cyber Domain," 70.

18 Fischer, "The Concept of Deterrence and its Applicability in the Cyber Domain," 90.

19 Tamara Maliarchuk, Yuriy Danyk, and Chad Briggs, "Hybrid Warfare and Cyber Effects in Energy Infrastructure," Connections: The Quarterly Journal 18, no. 1 (2019): 93-110. 
Весна Павичич завершает этот выпуск анализом положения Сербии на международной арене. ${ }^{20}$ Хотя европейская интеграция кажется очевидным выбором, интересы таких игроков, как Россия и Китай, и инструменты, которые они используют для продвижения своих интересов (в частности, те, которые используются Россией - изощренная пропаганда со ссылками на исторические связи, православное христианство, позиция по вопросу о независимости Косово, зависимость от поставок газа и нефти, сотрудничество в сфере обороны и т.д.), делают будущий путь Сербии неопределенным. Автор видит средства против гибридного влияния в комплексной безопасности, политическом и экономическом диалоге с Европейским союзом, более сильном гражданском обществе, более прозрачной и свободной прессе и сдвигах в политической риторике.

В этом специальном выпуске представлен обзор теории сдерживания и ее применимости на восточном фланге НАТО и Европы в отношении агрессивной политики и действий Российской Федерации, которые включают использование вооруженных сил против партнеров НАТО, Украины и Грузии, и более изощренные кибератаки и гибридные операции по влиянию как на членов НАТО, так и на партнеров.

Включенные здесь статьи рассматривают вопросы использования обычных вооруженных сил, киберсредств и способов повышения устойчивости вооруженных сил, экономики и общества. Меньше внимания уделялось применению концепции сдерживания к гибридной войне полного спектра, ${ }^{21}$ роли ядерного оружия в предотвращении fait accompli (ситуации, когда ставят перед свершившимся фактом), обращению вспять или сохранению достижений гибридной операции, ${ }^{22}$ а также взаимодействию кибер / гибридных атак и ядерных угроз. Все эти темы заслуживают дальнейшего рассмотрения в будущем специальном выпуске Connections: The Quarterly Journal.

20 Vesna Pavičić, "Serbia's Orientation Challenge and Ways to Overcome It," Connections: The Quarterly Journal 18, no. 1 (2019): 111-127.

21 Alexander Lanoszka, "Russian Hybrid Warfare and Extended Deterrence in Eastern Europe," International Affairs 92, no.1 (2016): 175-195; Andrew Radin, Hybrid Warfare in the Baltics: Threats and Potential Responses (Santa Monica, CA: RAND, 2017).

22 Peter Apps, "Commentary: Putin's Nuclear-tipped Hybrid War on the West," Reuters, March 2, 2018, https://uk.reuters.com/article/us-apps-russia-commentary-idUKKC N1GD6H2; Gustav Gressel, "Protecting Europe against Hybrid Threats," Policy Brief, European Council on Foreign Relations, June 25, 2019, https://ecfr.eu/publication/ protecting_europe_against_hybrid_threats/. 


\section{Отказ от ответственности}

Выраженные здесь взгляды являются исключительно взглядами автора и не отражают точку зрения Консорциума оборонных академий и институтов изучения безопасности ПрМ, участвующих организаций или редакторов Консорциума.

Издание Connections: The Quarterly Journal, том 18, 2019 осуществляется при поддержке правительства Соединенных Штатов.

\section{Об авторе}

Тодор Тагарев - профессор Института информационных и коммуникационных технологий Болгарской академии наук и руководитель его Центра менеджмента безопасности и обороны. Инженер по образованию, профессор Тагарев сочетает в себе опыт работы в правительстве с хорошими теоретическими знаниями и опытом в области кибернетики, исследований сложных систем и безопасности - потенциал, который он эффективно реализовал в многочисленных национальных и международных междисциплинарных исследованиях, включая текущие проекты по программе Горизонт 2020 в области кризисного менеджмента и кибербезопасности. https://orcid.org/0000-0003-4424-0201 